\title{
COMPARISON EFFECT BETWEEN PEGAGAN (Centella asiatica) EXTRACT AND PRAMIPEXOLE TOWARD LOCOMOTOR ACTIVITIES, $\alpha$ - SYNUCLEIN, AND NRF2 EXPRESSION IN ZEBRAFISH PARKINSON MODEL
}

\author{
Ayu Trisnawati ${ }^{1}$, Anasrulloh Anasrulloh ${ }^{1}$, Sri Budhi Rianawati ${ }^{1}$, Husnul Khotimah ${ }^{2}$, Mulyohadi Ali $^{2}$, Budi Susetya $^{3}$
}

Correspondence: emailayutrisna@gmail.com / anasrullohdamiri@gmail.com

${ }^{I}$ Department of Neurology Faculty of Medicine Brawijaya University, Malang, Indonesia.

${ }^{2}$ Department of Pharmacology, Faculty of Medicine Brawijaya University, Malang, Indonesia.

${ }^{3}$ Malang State Health Polytechnic, Malang, Indonesia.

\section{Article History: \\ Received: June 22, 2017 \\ Accepted: December 21, 2017 \\ Published: January 1, 2019 \\ Cite this as: \\ Trisnawati A, Anasrullah A, Rianawati SB, Khotimah H, Ali $M$, Susetya B. Comparison effect between pegagan (centella asiatica) extract and pramipexole toward locomotor activities, $\alpha$ - synuclein, and nrf 2 expression in zebrafish parkinson model. Malang Neurology Journal, 2019.5:5-13. DOI: \\ http://dx.doi.org/10.21776/ub.mnj .2019 .005 .01 .2}

\section{ABSTRACT}

Background: Parkinson disease is characterized with deposition of Lewy Bodies containing $\alpha$ synuclein happened due to the effect of chronic neuroinflammation that causes the death of dopaminergic neurons through oxidative stress processes, so it involves the response of Nuclear factor erythroid 2-like 2 (Nrf2). Centella asiatica (C.asiatica) contains antioxidant effect, inhibits the aggregation of $\alpha$-synuclein and improves the locomotor on Parkinson-model animals so it needs to compare to the standard medication.

Objective: To compare the C. asiatica extract and Pramipexole to the zebrafish Parkinson model by determining the locomotor activity, $\alpha$-synuclein expression, and Nrf2.

Methods: This study used six groups of zebrafish: negative control, rotenone rotenone $[5 \mu \mathrm{g} / \mathrm{L}]$, pramipexole1, 2, 3 (rotenone + pramipexole [3,5] ng/mL, [7] ng/mL, [14] ng/mL), and C. asiatica (rotenone + C. asiatica $[10] \mu \mathrm{g} / \mathrm{mL}$ ). The observations of locomotor activity of day 0,14 , and 28 were continued to the $\alpha$-synuclein immunohistochemical examination, and Nrf2 on the midbrain area.

Results: There are significant differences in locomotor activity on day 28 among the $C$. asiatica group with rotenone $(p<0,05)$, while there are no significant differences among the $C$. asiatica group with pramipexole [7] $\mathrm{ng} / \mathrm{mL}$ and [14] $\mathrm{ng} / \mathrm{mL}(\mathrm{p}>0,05) . \alpha$-synuclein expression of the $C$. asiatica group is the lowest and significantly different from all groups $(\mathrm{p}<0,05)$, while $\mathrm{Nr} 2$ had no significant differences $(\mathrm{p}>0,05)$.

Conclusion: $C$. asiatica extract [10] $\mu \mathrm{g} / \mathrm{mL}$ is equal to pramipexole [7] $\mathrm{ng} / \mathrm{mL}$ and [14] $\mathrm{ng} / \mathrm{mL}$ in improving locomotor activity, but $C$. asiatica extract holds excellence as it decreases $\alpha$-synuclein expression better than pramipexole, while Nrf2 expression shows no differences.

Keywords: Centella asiatica, locomotor activity, $\alpha$-synuclein, Nrf2, Parkinson disease, zebrafish

\section{Introduction}

Parkinson disease is a chronic and progressive aging disease characterized by hypokinesia, resting tremor, rigidity and postural instability along with Lewy bodies dominated by $\alpha$-synuclein protein. ${ }^{1,2}$ This disease can develop at the age between 45 years and 75 years, with prevalence in the world ranging from 160 per 100,000 population and incidence ranging from 20 per 100,000 population with a little bit higher incidence rates in industrial and agrarian countries with more pesticide use. ${ }^{2,3}$ In addition to genetic mutations, pesticide exposure offers $95 \%$ of sporadic occurrences of Parkinson's disease. ${ }^{1,4,5}$ Dopamine degradation in the substansia nigra pars compacta resulting from the death of dopaminergic neurons in Parkinson disease causes interference in movement coordination. ${ }^{6,7}$

Rotenone is a pesticide derived from Derris spp., Lonchocarpus spp., and Tephrosia spp., which can cause Parkinson disease through the hindrance to chain 1 complex of the mitochondrial respiration and causes oxidative stress, apoptosis that ends in selective cell death in dopaminergic neurons. ${ }^{8,910,11}$ Rotenone can also cause in vivo accumulation of $\alpha$-synuclein, beta-amyloid aggregation, tau hyperphosphorylation, loss of dopaminergic neurons and the death of striatal cell neurons and lead to decreased locomotor activity in experimental animals such as rats and zebrafish. $^{11,12,13,14,15,16}$

Treatment of Parkinson disease may be pharmacological therapy with drugs and non-pharmacological such as stem cells. ${ }^{16}$ for Parkinson disease presently intends to control the symptoms occurred by replacing dopamine (levodopa) which reduces in number or use agonist dopamine such as pramipexole that works directly on Dopamine D2 receptors. ${ }^{17.18}$ Both classes still have an insufficiency of the high incidence of dyskinesia and wearing-off after longterm use or after passing the "honeymoon period". Pramipexole is said to be better than levodopa because of the probability of smaller motor complications, and has neuroprotective effects on mitochondrial ROS inhibition, 
increased glutathione (GSH) and $\mathrm{BDNF}^{20,21,22,23,24}$ Currently, it is considered a therapy that can reduce the progressiveness of Parkinson disease through the hindrance in $\alpha$-synuclein aggregation formation which becomes one of the foundations of pathogenesis of Parkinson disease, and Nuclear factor erythroid 2-like 2 (Nrf2) is also considered to be the potential pharmacological target for neuroprotective therapy in Parkinson disease with the aim of enhancing the transcriptional activity of $\mathrm{Nrf} 2$ which is a transcription factor inducing the antioxidant gene. ${ }^{25}$

C.asiatica is herbal plants that have the main content such as asiatic acid, asiaticoside, madecassic acid, and madecassoside ${ }^{26.27}$ already known and used as an analgesic, antidepressant, antimicrobial, antiviral, immunomodulator in Southeast Asia and India. C.asiatica also holds antioxidant effect and neuro-protectan through the decreased superoxide dismutase (SOD), glutathione peroxidase $(\mathrm{GPx})$, and catalase, and it is also able to decrease $\alpha$-synuclein aggregation and increase BDNF on Parkinson model experimental animal. ${ }^{28,29,30,31,32,33}$ C.asiatica extract with a concentration of $10 \mu \mathrm{g} / \mathrm{L}$ provides an increase in tyrosine hydroxylase (TH) which is a tyrosine catalyst enzyme into L-dihydroxyphenylalanine (L-dopa) which later turns to dopamine, accompanied by improved locomotor activity, as well as decreased $\alpha$ synuclein expression in zebrafish Parkinson model. ${ }^{34,35}$

Zebrafish is one of the Parkinson model animals which have the structure and function of organs including a dopaminergic system with genetic homology with mammals reaching $70-80 \%$. Besides, zebrafish has other advantages like easy maintenance, affordable, and fast breeding. ${ }^{36,37,38,39}$ This study is an advanced study aimed to compare the effects of the administration of C.asiatica with concentration of $10 \mu \mathrm{g} / \mathrm{mL}$, which is known to have a positive effect on zebrafish Parkinson model in previous studies, with pramipexole [3,5 ng/mL], [7 ng/mL] and [14 $\mathrm{ng} / \mathrm{mL}]$ as one of medication for Parkinson disease. The study is established on zebrafish Parkinson model through rotenone exposure, then the locomotor activity, $\alpha$-synuclein expression, and $\mathrm{Nr} 2$ on the brain were valued.

\section{Methods}

This study is a laboratory experimental, randomized pre and post test control group design, using 30 zebrafish aged 8 10 months divided into 6 groups i.e group 1 negative control, group 2 positive control given rotenone [5] $\mu \mathrm{g} / \mathrm{L}$, group 3,4 , and 5 respectively were given rotenone [5] $\mu \mathrm{g} / \mathrm{L}$ plus pramipexole [3,5] ng/mL, [7] $\mathrm{ng} / \mathrm{mL}$ and [14] ng/mL, and group 6 were given rotenone $[5] \mu \mathrm{g} / \mathrm{mL}$ plus $C$. asiatica extract $[10] \mu \mathrm{g} / \mathrm{mL}$.

\section{Producing $C$. asiatica Extract}

C. asiatica was obtained from Balai Materia Medika Batu. The leaves and stems that are above the ground were washed and then dried using an oven with a temperature of $40^{\circ} \mathrm{C}$ then are well-blended. As much as $100 \mathrm{~g}$ of dried $C$. asiatica was soaked with $96 \%$ methanol to $900 \mathrm{ml}$ volume and shaken for \pm 30 minutes and was deposited for a night then filtered using filter paper. The solution of the extraction process is evaporated to $1 / 4$ of dry matter. The $C$. asiatica extract is stored in the freezer $4^{\circ} \mathrm{C}$ in plastic or glass bottles as stocks with a concentration of $10 \mathrm{~g} / \mathrm{L}(10$ $\mathrm{mg} / \mathrm{ml}$ ) in distilled water solution.

\section{Producing Pramipexole Solution}

Pramipexole (SIGMA A1237) in the form of $10 \mathrm{mg}$ powder was dissolved in $1 \mathrm{ml}$ of distilled water then $20 \mu \mathrm{l}$ of the solution was dissolved in $1980 \mu \mathrm{l}$ distilled water to be a stock solution. Pramipexole [3.5] ng/ml, [7] ng/ml, and [14] $\mathrm{ng} / \mathrm{ml}$ were obtained by taking stock solutions as much as $70 \mu \mathrm{l}, 140 \mu \mathrm{l}$, and $280 \mu \mathrm{l}$.

\section{Producing Rotenone Solution}

Rotenone (SIGMA 8875) powder weighed $20 \mathrm{mg}$ was dissolved in $1 \mathrm{ml}$ of DMSO (dimethyl sulfoxide) then diluted to produce $2 \times 105 \mu \mathrm{g} / \mathrm{l}$ stock solutions with rotenone replacement solution from $2 \times 107 \mu \mathrm{g} / 1$ stock as much as $10 \mu \mathrm{l}$, then added distilled water as much as $990 \mu \mathrm{l}$ (DMSO level 1\%). A concentration of $5 \mu \mathrm{g} / 1$ was administered by giving rotenone from $2 \times 105 \mu \mathrm{g} / 1$ stock as much as $50 \mu \mathrm{l}$ (DMSO concentration of $0.25 \mathrm{ppm}$ ).

Administration of Rotenone, Pramipexole, and $C$. asiatica on Zabra Fish

Administration of rotenone, pramipexole, and $C$. asiatica extract is dissolved into an aquarium containing $2 \mathrm{~L}$ of fresh water that was previously filtered using Pure $I t^{\circledR}$ according to the respective concentration. Aquarium water replacement, giving of rotenone, pramipexole, and the $C$. asiatica extract was administered every 2 days.

\section{Measuring Locomotor Activity}

Locomotor activity was carried out in the aquarium containing $2 \mathrm{~L}$ of water measuring $25 \times 16.5 \times 12.5 \mathrm{~cm}$ by giving three vertical lines at the bottom of the aquarium so as to divide it into 4 sections measuring $6.25 \mathrm{~cm}$. Each wall of the aquarium was closed by using white paper to reduce environmental influences. Zebrafish were allowed to move actively, be observed and recorded using a video camera for 5 minutes with previous adaptation for 3 minutes. The movement of the fish was calculated from the video recording by counting and summing the fish move crossing the striped area for 5 minutes. ${ }^{40}$

\section{Sample Preparation of the Zebrafish Brain}

After 28 days, the zebrafish was sacrificed by placing on an amount of ice with a little water. After not showing a spontaneous movement, it is decapitated, then the fish head was taken, inserted into a bottle filled with formalin buffer solution and stored at room temperature. Furthermore, the brain tissue was incised and made a slide with paraffin block. Cutting was done sagittally with a thickness of 0.4 $\mu \mathrm{M}$ starting from the center of the head of the zebrafish towards the lateral.

\section{Calculation of $\alpha$ - synuclein Expression and Nrf2 with Immunohistochemistry}

Before the slide was deparaffinized, the slide was preheated at $60^{\circ} \mathrm{C}$ for 60 minutes in a dry incubator and then added with the following solutions in order: xylol (2x10 minutes), absolute ethanol (2x10 minutes), 90\% ethanol (1x5 minutes) ethanol $80 \%(1 \times 5 \mathrm{~min})$, ethanol $70 \%(1 \times 5 \mathrm{~min})$, sterile distilled water (aquadest) $(3 \times 5 \mathrm{~min})$ followed by retrieval antigen with chamber decloaking. The slides which were prepared for Immunohistochemical examination were dripped with $4 \% \mathrm{H}_{2} \mathrm{O}_{2}$ in methanol, and inserted chamber for 15 minutes and then washed with sterile PBS (paraformaldehyde buffer solution) for $3 \times 5$ minute. After that, a non-specific protein blocking the process by dripping the background sniper (Biocare 
Startrex)is established for 30 minutes at room temperature and then washed with sterile PBS for $3 \times 5$ minutes.

The incubation process of primary antibodies was administered by dripping the primary antibody $\alpha$-synuclein (Santa Cruz) or Nrf2 (Santa Cruz) according to the vendor's manual procedure. Furthermore, the slide was dripped with DAB chromagen (DAB chromogen: $\mathrm{DAB}$ buffer $=1: 40$ ), incubated for 5 minutes at room temperature, washed with sterile PBS for $3 \times 5 \mathrm{~min}$, and then rinsed with distilled water for $3 \times 5$ minutes. After that, the slides were given counterstain with Mayer's Hematoxylen, by dripping Mayer's Hematoxylen: distilled water with comparison $1: 20$, incubated for five minutes at room temperature, and rinsed with distilled water. The last step of immunohistochemical coloring is the mounting process, with Entellan, then the sides were dried and the observation using microscope was administered.

The calculation of cell total expressing $\alpha$-synuclein and $\mathrm{Nr} 2$ was done by using "hot spot" method aided with binoculars microscope in 10 different fields of view in the midbrain area $(M=1000 x)$. Positive cells showed a brown-stained cytoplasm. $^{33}$

\section{Processing and Analysis of Data}

All data were statistically analyzed using SPSS 20 software using one-way ANOVA and followed by a post hoc test least significant difference (LSD) to compare mean differences between groups of experimental animals. Statistical test results are significant if the value of $\mathrm{p}<0.05$.

\section{Results}

\section{Locomotor Activity}

The locomotor activity of zebrafish within five minutes in day 0,14 , and 28 in all treatment groups and the analysis result off one-way ANOVA test can be seen in Table 1, the analysis result of post hoc LSD can be seen in Figure 1, and the curve of time series of the entire groups is presented in Figure2.

Table 1. The comparison of locomotor activity and the analysis of one-way ANOVA test at various times of each treatment group.

\begin{tabular}{cccc}
\hline \multirow{2}{*}{ Group } & \multicolumn{3}{c}{ Number of Locomotor Activity per 5 } \\
& Day 0 & Day 14 & Day 28 \\
\cline { 2 - 4 } Control (-) & 113.67 & 193.00 & 144.67 \\
& $( \pm 11.06)$ & $( \pm 5.57)$ & $( \pm 12.66)$ \\
Rotenone & 112.00 & 101.00 & 67.00 \\
& $( \pm 10.44)$ & $( \pm 6.08)$ & $( \pm 7.94)$ \\
$\mathrm{R}+$ Pmx 3,5 & 119.33 & 83.67 & 142.00 \\
& $( \pm 14.01)$ & $( \pm 8.39)$ & $( \pm 9.85)$ \\
$\mathrm{R}+$ Pmx 7 & 86.67 & 96.67 & 100.00 \\
& $( \pm 1.15)$ & $( \pm 10.26)$ & $( \pm 2.00)$ \\
$\mathrm{R}+$ Pmx 14 & 92.67 & 97.00 & 101.00 \\
& $( \pm 9.02)$ & $( \pm 6.08)$ & $( \pm 25.71)$ \\
$\mathrm{R}+$ C. & 109.00 & 97.67 & 97.33 \\
asiatica & & $( \pm 11.02)$ & $( \pm 6.66)$ \\
& & &
\end{tabular}

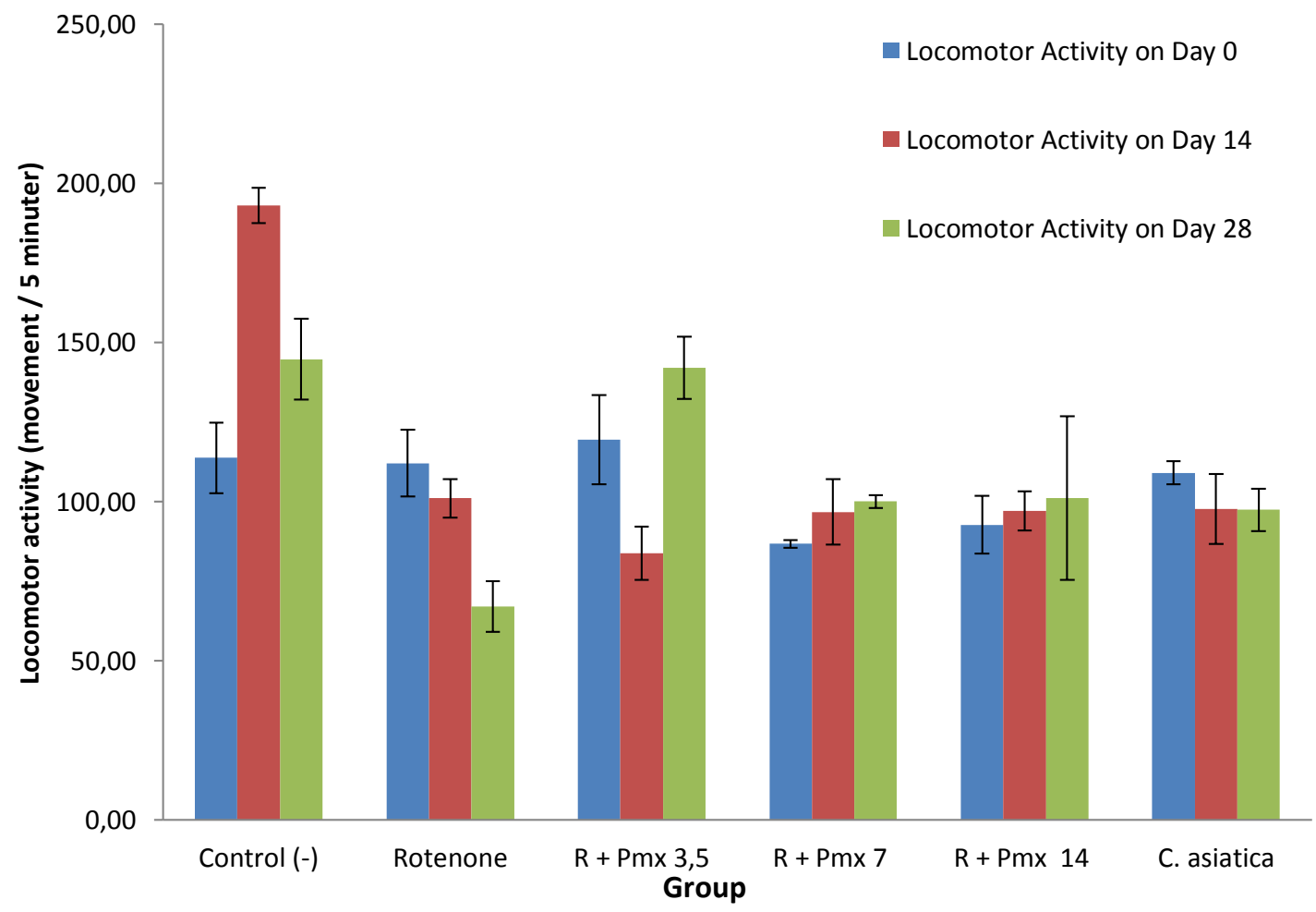

$\mathrm{R}$ : rotenone, Pmx: pramipexole

Figure 1. LSD test results analysis of zebrafish locomotor activity on day 0,14 , and 28. 


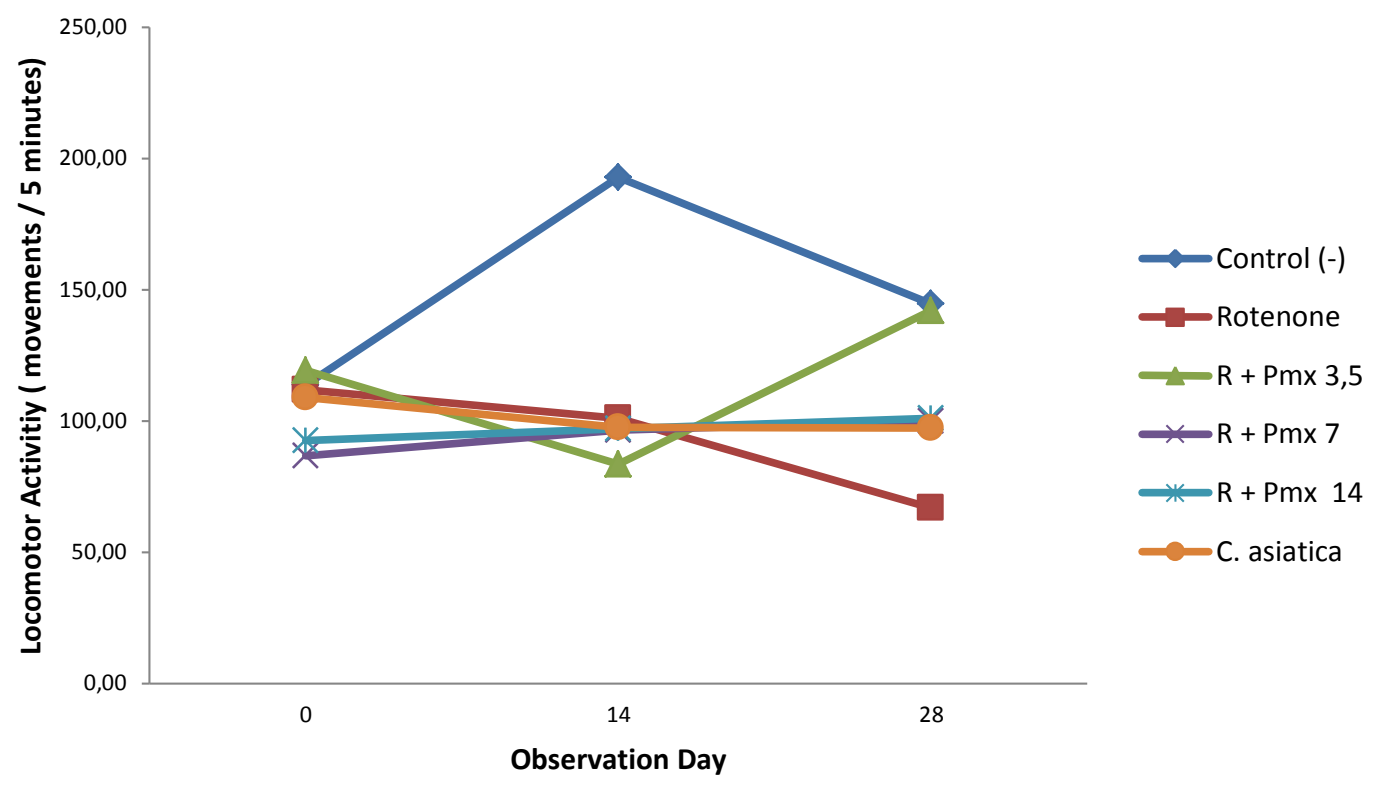

Figure 2. The zebrafish locomotor activity on day 0,14 , and 28 .

The result of one-way ANOVA test showed the mean value of the locomotor activity of all treatment groups on day 0 , 14 , and 28 is significantly different $(\mathrm{p}<0.05)$. Later, it was continued with post hoc test LSD, and it was found in the observation day 0 significant difference among control groups, rotenone, pramipexole [3.5] ng/mL, and C. asiatica with pramipexole [7] $\mathrm{ng} / \mathrm{mL}$ and [14] $\mathrm{ng} / \mathrm{mL}$ On the rotenone group showed significant progressive degradation on day 14 and 28. Pramipexole [3.5] ng/mL on day 14 showed degradation but it was back increased on day 28 . Pramipexole [7] ng/mL and [14] ng/mL and C. asiatica was able to maintain the locomotor activity on day 0,14 , and 28.

\section{Immunohistochemical Examination}

The observation of $\alpha$-synuclein and the Nrf2 expression on zebrafish was carried out in the midbrain area in line with Figure 3.

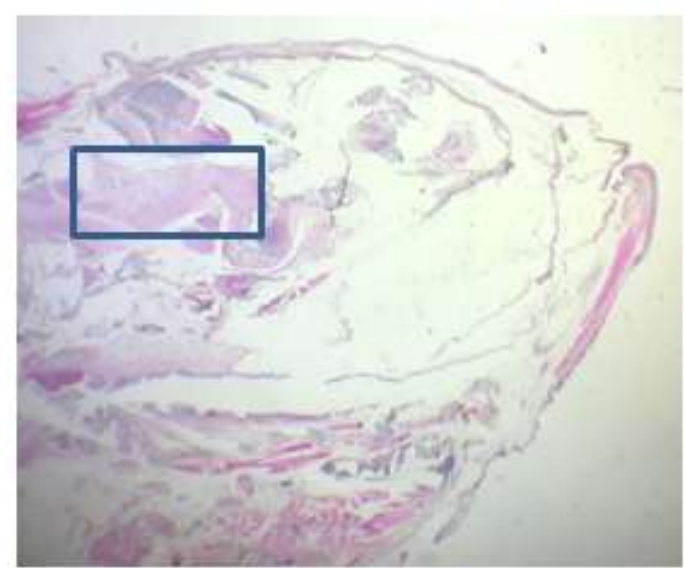

Fugure 3. Sagittal Incision on zebrafish head with hematoxilleneosin coloring. The area inside the blue box is the area in which the immunohistochemical observation was established.
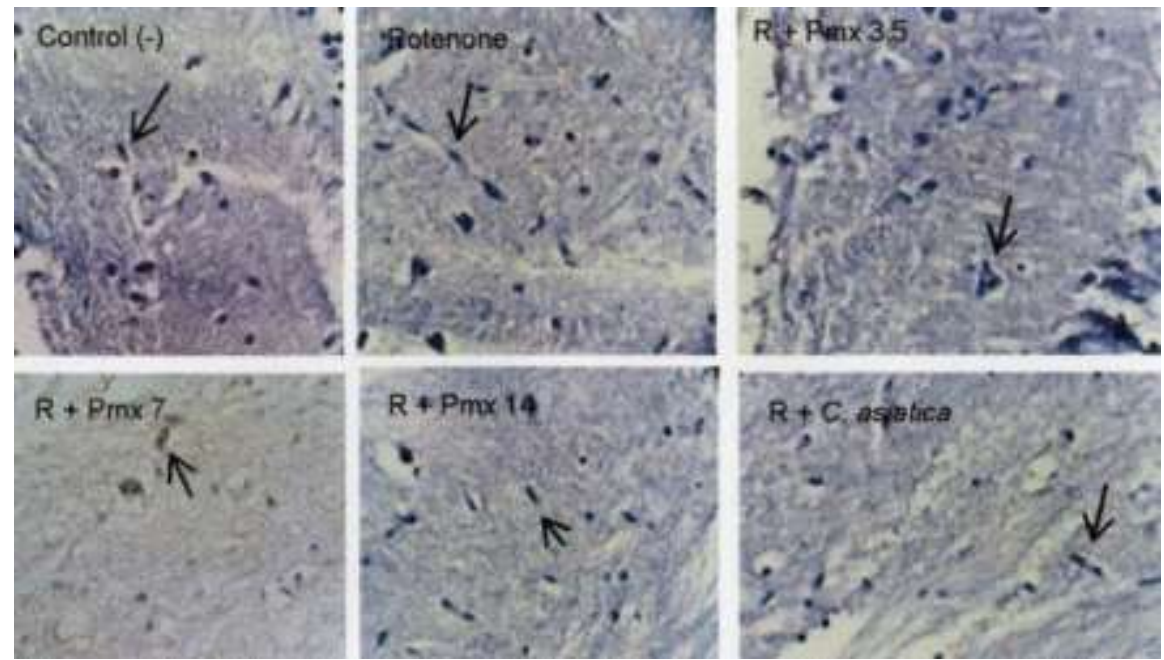

Figure 4. $\alpha$-synuclein Expression observed with on the midbrain area of each group (M=1000x). Arrow $\uparrow$ represented the cell expressing $\alpha$-synuclein, having brown-stained cytoplasm. Rot: rotenone, Pmx: pramipexole. 
The calculation of $\alpha$-synuclein expression on each group analyzed by using one-way ANOVA test can be seen in Table 2 and the analysis result of post hoc LSD can be seen in Figure 5.

Table 2. Mean of $\alpha$-synuclein expression on day 28 and the analysis result of one-way ANOVA of the zebrafish in each group.

\begin{tabular}{lrrr}
\hline \multicolumn{1}{c}{ Group } & $\begin{array}{c}\alpha \text {-synuclein expression } \\
( \pm \mathrm{SD})\end{array}$ & Sign. (p) \\
\hline Control (-) & 33.67 & $( \pm 1.53)$ & 0.014 \\
Rotenone & 66 & $( \pm 5.57)$ & \\
$\mathrm{R}+$ Pmx 3,5 & 53.33 & $( \pm 11.37)$ & \\
$\mathrm{R}+$ Pmx 7 & 53.33 & $( \pm 9.50)$ & \\
$\mathrm{R}+$ Pmx 14 & 49 & $( \pm 5.57)$ & \\
$\mathrm{R}+$ C. asiatica & 47.33 & $( \pm 12.06)$ & \\
\hline
\end{tabular}

The result of one-way ANOVA test showed the $\alpha$-synuclein expression among groups were significantly different ( $p<0.05)$. It was continued with Post hoc test LSD and it was obtained that the rotenone group showed the highest $\alpha$ synuclein expression, but there was no significant difference with the pramipexole group with a concentration of $3.5 \mathrm{ng} / \mathrm{mL}$ and $7 \mathrm{ng} / \mathrm{mL}$. C. asiatica held the lowest value and was not significantly different from the control group.

\section{Nrf2 Expression}

The result of the Nrf2 immunohistochemical on each group is presented in Figure 6 with using binoculars microscope on the field of view $10(\mathrm{M}=1000 \mathrm{x})$. The positive cell will have brown-stained cytoplasm.

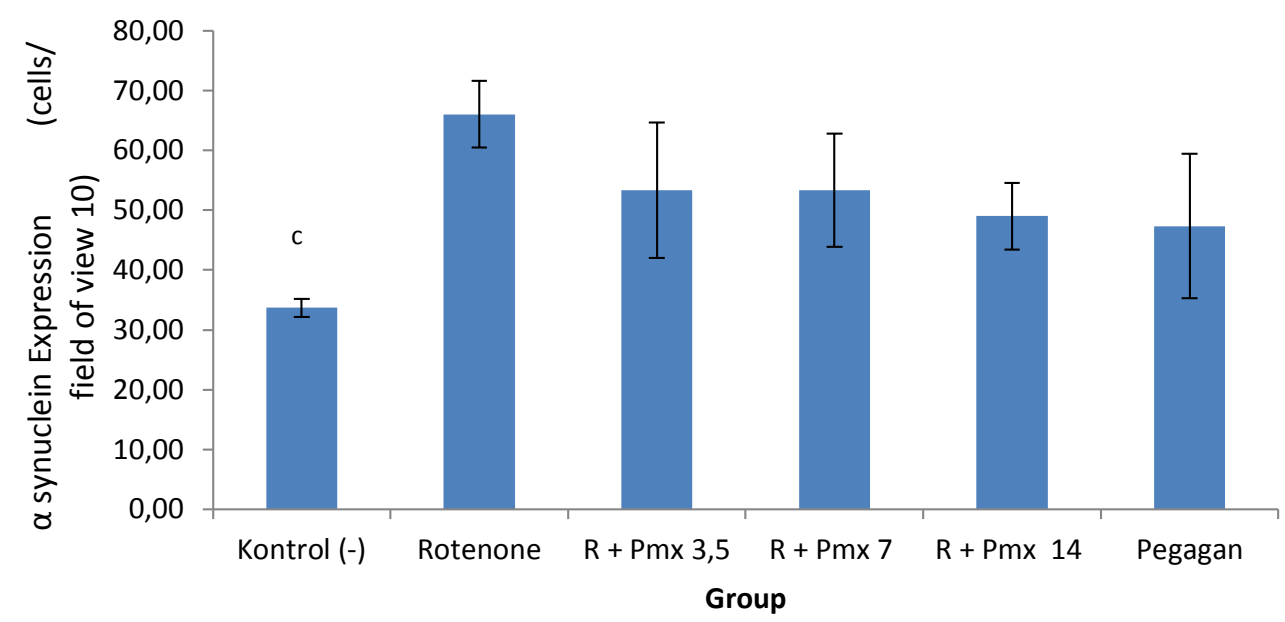

Figure 5. The Mean of the $\alpha$-synuclein and LSD test. Rot: rotenone, Pmx: pramipexole.
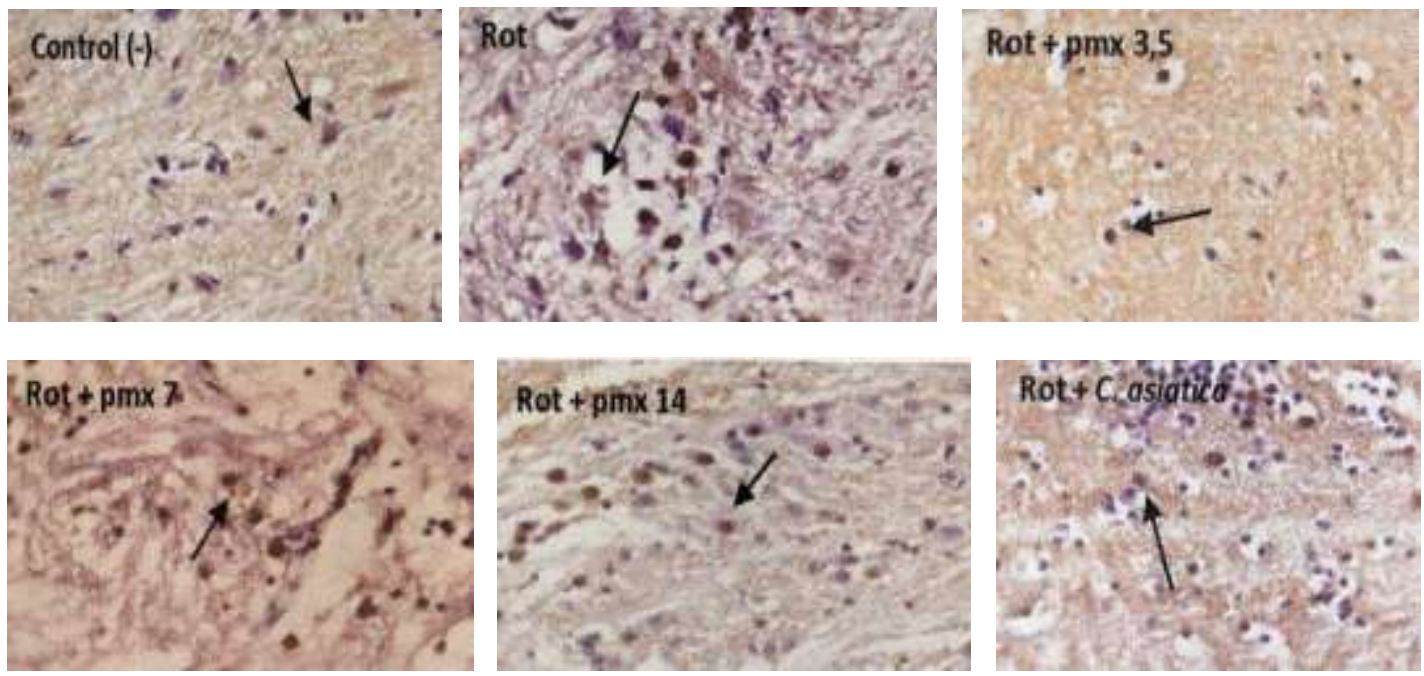

Figure 6. Nrf2 expression seen in the midbrain area of each group $(\mathrm{M}=1000 \mathrm{x})$. Arrow represented the cell expressing Nrf2, having brown-stained cytoplasm. Rot: rotenone, Pmx: pramipexole.

The calculation of Nrf2 expression on each treatment group analyzed by using one-way ANOVA test can be seen in
Table 3 and the analysis result of post hoc LSD can be seen in Figure 7. 
Table 3. Mean of Nrf2 expression on day 28 and the analysis result of one-way ANOVA of the zebrafish in each group.

\begin{tabular}{llll}
\hline \multicolumn{1}{c}{ Group } & \multicolumn{1}{c}{$\begin{array}{c}\text { Nrf2 expression } \\
( \pm \text { SD })\end{array}$} & Sign. (p) \\
\hline Control (-) & 14.67 & $( \pm 4.62)$ & 0.294 \\
Rotenone & 21 & $( \pm 3.00)$ & \\
R + Pmx 3,5 & 13.67 & $( \pm 0.58)$ & \\
R + Pmx 7 & 21 & $( \pm 8.89)$ & \\
R + Pmx 14 & 29 & $( \pm 17.78$ & \\
R + C. asiatica & 26.67 & $( \pm 8.08)$ & \\
\hline
\end{tabular}

R: rotenone, Pmx: pramipexole

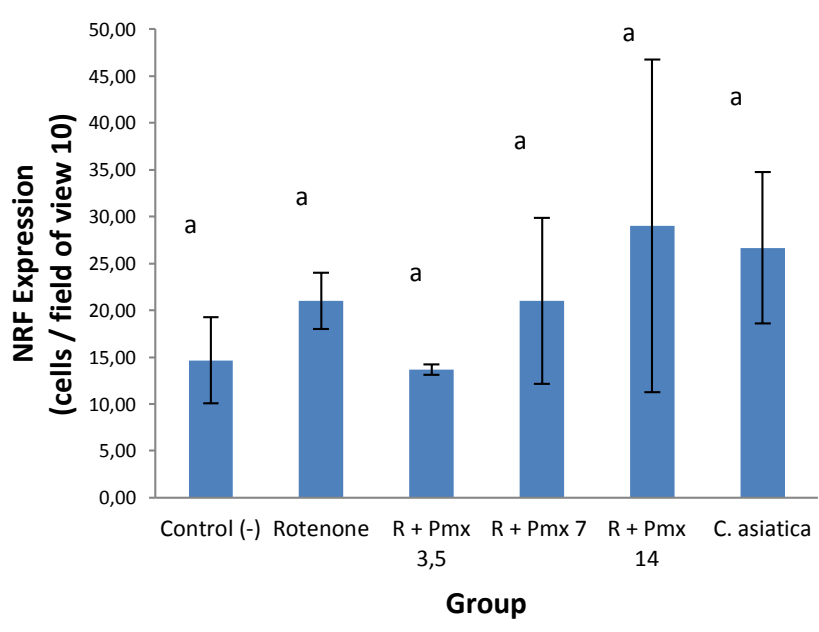

Figure 7. Graph of Mean of the Nrf2 and LSD test. Rot: rotenone, Pmx: pramipexole.

The result of one-way ANOVA showed that the sig value (p-value) 0.294 is greater than alpha $0.05(\mathrm{p}<0.05)$, thus it can be concluded that the treatment group had no significant effect on Nrf2.

\section{Discussion}

\section{Locomotor Activity}

Zebrafish holds a basic motor response of locomotor activity including the speed of swimming, distance, and rotational speed. $^{41}$ Zebrafish are sensitive to the administration of neurotoxins including rotenone pesticides that may cause decreased dopaminergic neurons, thyroxine hydroxylase $(\mathrm{TH})$, increased $\alpha$-synuclein levels, oxidative damage, and increased apoptotic activity. ${ }^{14,42}$ In this study, locomotor activity in the rotenone group decreased progressively until day 28 . This result was in line with the previous research where [5] $\mu \mathrm{g} / \mathrm{L}$ rotenone exposure showed decreased motility, whereas [10] $\mu \mathrm{g} / \mathrm{L}$ could cause death in zebrafish, ${ }^{40,43}$ in line with the study conducted by Wrangel et al., 2015, that rotenone-exposed rat showed a general idea of Parkinson disease including decreased motor activity accompanied by loss of dopamine in the nigrostriatal system. ${ }^{44}$ Similarly, a 28 -day sub-chronic rotenone administration in zebrafish can lead to decreased dopamine, increased $\alpha$-synuclein expression and aggregation resulting in the apoptosis of dopaminergic neuron cells leading to the symptoms of parkinsonism throughout decreased locomotor activity. ${ }^{43}$
This study showed that $C$. asiatica extract is able to maintain the locomotor activity until day 28 better than the administration of rotenone only. This result is in line with the previous study, where the administration of $C$. asiatica [2,5] $\mu \mathrm{g} / \mathrm{L}$ and [10] $\mu \mathrm{g} / \mathrm{mL}$ to zebrafish exposed by rotenone can increase motility. ${ }^{31}$ The administration of the C. asiatica active content such as madecassoside and asiaticoside can prevent the decreased motor activity in rats Parkinson model. Locomotor activity is connected to the level of dopamine, in which the administration of that active content is able to protect dopaminergic neurons on rats Parkinson model exposed with MTPT through the increased glutathione (GSH) which is an antioxidant and the decreased $\mathrm{Bcl} 2 / \mathrm{Bax}_{\text {ratio }}{ }^{45,46}$ besides, the $C$. asiatica extract is able to decrease apoptosis of dopaminergic neurons in zebrafish Parkinson model exposed with rotenone. $^{33}$

Pramipexole [3,5] ng/mL showed the highest improved locomotor activity on day 28 and it did not differ significantly with the control group, but on day 14, it had decreased, while [7] $\mathrm{ng} / \mathrm{mL}$ and [14] $\mathrm{ng} / \mathrm{mL}$ are similar to C. asiatica capable of maintaining locomotor until day 28 .

\section{$\alpha$-synuclein Expression}

$\alpha$-synuclein protein is the main component of Lewy bodies that becomes one of the pathogenesis of Parkinson disease found in both sporadic and genetic Parkinson disease, which are normally in synapses in unfolded form, but at high concentrations may aggregate. ${ }^{3}$ A number of pesticides including rotenone can cause $\alpha$-synuclein aggregation in vitro as well as in neuron cultured cells so rotenone can be one of the factors causing Parkinson's disease. $^{47,15}$

This study showed all groups exposed to rotenone experienced increased $\alpha$-synuclein expression if compared to the negative control, with the highest increase was $100 \%$ obtained in rotenone group. This is in line with the study conducted by Khotimah, Ali et al., 2015 showing the increased $\alpha$-synuclein aggregation up to $300 \%$ in zebrafish midbrain area exposed with rotenone and then connected to the decreased locomotor activity describing the clinical form of bradykinesia parkinsonism occurring in Parkinson disease. $^{34}$

$\alpha$-synuclein expression in $C$. asiatica group showed the lowest result and it did not differ significantly with the control group, thus it can be concluded that the administration of $C$. asiatica extract is able to perform the decreased $\alpha$-synuclein expression exposed with rotenone. This is in line with the previous study in which the administration of $C$. asiatica extract [5] and [10] $\mu \mathrm{g} / \mathrm{mL}$ is able to decrease $\alpha$-synuclein aggregation if given with rotenone. ${ }^{34} C$. asiatica extract is able to inhibit the change of $\alpha$-synuclein monomer form to oligomers by maintaining $\alpha$-synuclein in spiral form, and inhibit the oligomers enduring to form aggregated filaments. ${ }^{48}$

Pramipexole group [3.5] ng/mL, [7] ng/mL, and [14] ng/mL showed that the $\alpha$-synuclein expression did not significantly differ from $C$. asiatica, but pramipexole [14] $\mathrm{ng} / \mathrm{mL}$ was better compared to the other two concentrations because they were still significantly different from rotenone group.

Excessive $\alpha$-synuclein aggregation can directly inhibit $\mathrm{TH}$ activity resulting in decreased dopamine, it can also inhibit the work of vesicular monoamine transporter 2 (VMAT2) 
used in the inclusion of dopamine cytosol into vesicles, so that the accumulation of dopamine in the cytosol can increase oxidative stress that leads it to the death of dopaminergic neurone cell. ${ }^{49,50}$

\section{Nrf2 Expression}

Nrf2 is a transcriptional factor that induces antioxidant genes and detoxification enzymes and has a major role in protecting various organs and tissues including the heart, kidneys, liver, and brain of the body from environmental oxidants such as electrophiles, reactive oxygen species (ROS) and reactive nitrogen species (RNS). ${ }^{51,52}$

This study showed that there was no significant difference statistically of the Nrf2 expression in all treatment groups. The high expression of Nrf2 in the negative control group may be related to the Nrf2 function as a self-defense mechanism for the cell. Activation and inactivation of $\mathrm{Nrf} 2$ are required to maintain the redox cell homeostasis. ${ }^{51}$ The natural process of natural oxidation in the fish body can also activate $\mathrm{Nrf} 2$.

The nrf2 expression on treatment group with rotenone, pramipexole, and $C$. asiatica may be related to the subchronic oxidant exposure causing the continuous expression of Nrf2. This result was different from the study on Hep G2 culture cells induced by tert-butyl hydroperoxide (t-BHP) by modulating Nrf2 signaling through activation of Akt and ERK. ${ }^{53}$ While Toninelli et al., was able to prove the antioxidant role of dopamine pramipexole agonists through SH-SY5Y neuroblastoma culture cells where pramipexole prevents cell death induced by $\mathrm{H}_{2} \mathrm{O}_{2}$ and inhibits the formation of mitochondrial ROS. ${ }^{23}$

Associated with the phenomenon of locomotory enhancement in pramipexole and $C$. asiatica group, it is required to do further research to know whether there is a high expression of $\mathrm{Nrf} 2$ in each group which is proportional to the oxidation process that goes on a cell such as examination of MDA.

\section{Conclusion}

Rotenone exposure is able to decrease locomotor activity along with an increase in $\alpha$-synuclein aggregation of up to $100 \%$ in zebrafish midbrain area. $C$. asiatica extract and pramipexole [7] $\mathrm{ng} / \mathrm{mL}$ and [14] $\mathrm{ng} / \mathrm{mL}$ were able to improve equivalent locomotor activity, but $C$. asiatica has an advantage because it decreases the lowest $\alpha$-synuclein expression, whereas $\mathrm{Nrf} 2$ expression among $C$. asiatica extracts and pramipexole did not differ in this study.

\section{Acknowledgement}

The author thanks to Brawijaya University and Saiful Anwar General Hospital, Malang, East Java, Indonesia for facilitating this research.

\section{References}

1. Ropper AH, Brown RH. Adams and Victor's Principles of Neurology. 8th ed. McGraw-Hill; 2005

2. PERDOSSI. Gangguan gerak. Kelompok Studi Gangguan Gerak Persatuan Dokter Spesialis Saraf Indonesia, editor. Jakarta; 2013
3. Ropper AH, Samuels MA, Klein JP. Adams and Victor's Principles of Neurology. 10th ed. McGrawHill Education; 2014

4. Narayan S, Liew Z, Paul K, Lee P, Sinsheimer JS, Bronstein JM, et al. Household organophosphorus pesticide use and parkinson's disease. International Journal of Epidemiology; 2013.42;1476-85. DOI: 10.1093/ije/dyt170

5. Dauer W, Przedborski S. Parkinson's disease: mechanisms and models. Neuron; 2003.39:889-909 DOI: https://doi.org/10.1016/S0896-6273(03)00568-3

6. Howells DW, Porritt MJ, Wong JYF, Batchelor PE, Kalnins R. Reduced bdnf mrna expression in the parkinson's disease substantia nigra. Experimental Neurology; 2000;135:127-35. DOI: 10.1006/exnr.2000.7483

7. Baquet ZC, Bickford PC, Jones KR. Brain-derived neurotrophic factor is required for the establishment of the proper number of dopaminergic neurons in the substantia nigra pars compacta. J Neurosci The Journal of Neuroscience; 2005.25(26):6251-9. DOI: 10.1523/JNEUROSCI.4601-04.2005

8. Greenamyre JT, Sherer TB, Betarbet R, Panov AV. Complex i and parkinson's disease. IUBMB Life; 2001.52:135-41

9. Sherer TB, Betarbet R, Testa CM, Seo BB, Richardson JR, Kim JH, et al. Mechanism of toxicity in rotenone models of parkinson's disease. J Neurosci The Journal of Neuroscience; 2003.23(34):10756-64

10. Keane PC, Kurzawa M, Blain PG, Morris CM. Mitochondrial dysfunction in parkinson's disease. 2011;2011(Figure 1)

11. Betarbet R, Canet-Avilesb RM, Sherera TB, Mastroberardinoa PG, McLendonb C, Kima J-H, et al. Intersecting pathways to neurodegeneration in parkinson's disease: effects of the pesticide rotenone on $\mathrm{dj}-1, \alpha$-synuclein, and the ubiquitin-proteasome system. Neurobiol Dis; 2006.22(2):404-20. DOI: 10.1016/j.nbd.2005.12.003

12. Blesa J, Phani S, Jackson-lewis V, Przedborski S. Classic and new animal models of parkinson's disease. Journal of Biomedicine and Biotechnology; 2012;2012. DOI: 10.1155/2012/845618

13. Charbel E-H M, Rusnak M, Hailu A, Sidhu A, Fricke S. NIH Public Access. 2012;209(1):224-33

14. Martel S, Y.Keow J, Ekker M. Rotenone neurotoxicity causes dopamine neuron loss in zebrafish. University of Ottawa Journal of Medicine; 2015.5(2). DOI: https://doi.org/10.18192/uojm.v5i2.1413

15. Chaves RS, Melo TQ, Martins SA, Ferrari MFR. Protein aggregation containing beta-amyloid, alphasynuclein and hyperphosphorylated tau in cultured cells of the hippocampus, substantia nigra and locus coeruleus after rotenone exposure. BMC Neuroscience; 2010.11. DOI: 10.1186/1471-2202-11144

16. Rahayu M, Kurniawan SN, Anggraini DJ. The effect of beta glucan of saccharomyces cerevisae on the increase of the number of brain cells in substantia nigra brain of parkinson's wistar strain rat (rattus norvegicus) model induced with rotenone. Malang Neurology Journal; 2015.3:17-22. DOI: http://dx.doi.org/10.21776/ub.mnj.2015.001.01.4 
17. Gunawan G, Dalhar M, Kurniawan SN. Parkinson and stem cell therapy. Malang Neurology Journal; 2017.3:39-46.

DOI: http://dx.doi.org/10.21776/ub.mnj.2017.003.01.7

18. Brooks D. Dopamine agonists: their role in the treatment of parkinson's disease. Journal Neurology Neurosurgery Psychiatry; 2000.68:685-90. DOI: 10.1136/jnnp.68.6.685

19. Ishibashi K, Ishii K, Oda K, Mizusawa H, Ishiwata K. Binding of pramipexole to extrastriatal dopamine $\mathrm{d}$ 2/d 3 receptors in the human brain: a positron emission tomography study using $11 \mathrm{c}-\mathrm{flb} 457$. PLoS One; 2011.6(3):5-10. DOI: 10.1371/journal.pone.0017723

20. The Parkinson Study Group. Pramipexole vs levodopa as initial treatment for parkinson disease. J Am Med Assoc; 2015.61(July 2004):1044-54. DOI: 10.1001/archneur.61.7.1044

21. Ling ZD, Robie HC, Tong CW, Carvey PM. Both the antioxidant and d 3 agonist actions of pramipexole mediate its neuroprotective actions in mesencephalic cultures 1. Neurol Experimental Study; 1999.289(1):202-10. PubMed: https://www.ncbi.nlm.nih.gov/pubmed/10087005

22. Le WD, Jankovic J, Xie W, Appel SH. Antioxidant property of pramipexole independent of dopamine receptor activation in neuroprotection. journal of neural transmission; 2000.107:1165-73. DOI: $10.1007 / \mathrm{s} 007020070030$

23. Ferrari-toninelli G, Maccarinelli G, Uberti D, Buerger E, Memo M. Mitochondria-targeted antioxidant effects of s $(-)$ and $\mathrm{r}(+)$ pramipexole; 2010.1-6. DOI: $10.1186 / 1471-2210-10-2$

24. Imamura $\mathrm{K}$, Takeshima $\mathrm{T}$, Nakaso $\mathrm{K}$, Ito $\mathrm{S}$, Nakashima K. Pramipexole has astrocyte-mediated neuroprotective effects against lactacystin toxicity. Neuroscience Letters; 2008.440:97-102. DOI: 10.1016/j.neulet.2008.05.067

25. Cuadrado A, Moreno-murciano P. The transcription factor nrf2 as a new therapeutic target in parkinson's disease. Inf UK Journal Expert Opinion on Therapeutic Targets; 2009.319-29. DOI: $10.1517 / 13543780802716501$

26. Kim W, Kim J, Veriansyah B, Kim J, Lee Y, Oh S, et al. The journal of supercritical fluids extraction of bioactive components from centella asiatica using subcritical water; 2009.48:211-6. DOI: 10.1016/j.supflu.2008.11.007

27. Hashim P, Sidek H, Helan MHM, Sabery A, Palanisamy UD, Ilham M. Triterpene composition and bioactivities of centella asiatica. Molecules; 2011.1310-22. DOI: 10.3390/molecules16021310

28. Brinkhaus B, Lindner M, Schupp D, Hahn EG. Chemical, the pharmacological and clinical profile of the east asian medical plant centella asiatica. Phytomedicine; 2000.7(5). PubMed: https://www.ncbi.nlm.nih.gov/pubmed/11081995

29. Hussin M, Hamid AA, Mohamad S, Saari N, Bakar F, Dek SP. Modulation of lipid metabolism by centella asiatica in oxidative stress rats. J FOOD Sci; 2009.74(2):72-8. $\quad$ DOI: $\quad 10.1111 / \mathrm{j} .1750$ 3841.2009.01045.x

30. Haleagrahara N, Ponnusamy K. Neuroprotective effect of centella asiatica extract (cae) on experimentally induced parkinsonism in aged Sprague-Dawley rats. J Toxicol Sci; 2010.35(1):41-7. PubMed:

https://www.ncbi.nlm.nih.gov/pubmed/20118623

31. Siddique $\mathrm{YH}, \mathrm{Naz}$ F, Jyoti S, Fatima A, Khanam S, Ali F, et al. Effect of centella asiatica leaf extract on the dietary supplementation in transgenic drosophila model of parkinson' s disease. Hindawi Publ Corp; 2014. DOI: $10.1155 / 2014 / 262058$

32. Zhao Y, Shu P, Zhang Y, Lin L, Zhou H, Xu Z, et al. Effect of centella asiatica on oxidative stress and lipid metabolism in hyperlipidemic animal models. Hindawi Publ Corp; 2014.2014. DOI: $10.1155 / 2014 / 154295$

33. Khotimah H, Sumitro SB, Ali M, Widodo MA. Standardized centella asiatica increased brain-derived neurotrophic factor and decreased apoptosis of dopaminergic neuron in rotenone- induced zebrafish. GSTF J Psychology; 2015.2(1):22-7

34. Khotimah H, Ali M, Sumitro SB, Widodo MA. Decreasing a-synuclein aggregation by methanolic extract of centella asiatica in zebrafish parkinson's model. Asian Pac J Trop Biomed. Elsevier (Singapore) Pte Ltd; 2015.5(11):948-54. DOI: http://dx.doi.org/10.1016/j.apjtb.2015.07.024

35. Hanum S, Widodo MA, Rahayu M. Pengaruh ekstrak c. asiatica (centella asiatica) terhadap ekspresi tirosin hidroksilase (th) serta aktivitas lokomotor ikan zebra (danio rerio) the effect of centella asiatica's extract towards the expression of tyrosine hydroxylase (th) and locomot. Jurnal Kedokteran Brawijaya; 2016.29(2):99-103

36. Gerlai R, Lahav M, Guo S, Rosenthal A. Drinks like a fish: zebrafish (danio rerio) as a behavior genetic model to study alcohol effects. Pharmacol Biochem Behav; 2001.67(2000):773-82

37. Xi Y, Noble S, Ekker M. Modeling neurodegeneration in zebrafish. Current Neurology and Neuroscience Reports; 2011.11(3):274-82. DOI: 10.1007/s11910011-0182-2

38. Gerlai R. Using zebrafish to unravel the genetics of complex brain disorders. Curr Top Behave Neurosci; 2012.12:3-24. DOI: 10.1007/7854_2011_180

39. Steele SL, Prykhozhij S V., Berman JN. Zebrafish as a model system for mitochondrial biology and diseases. Translational Research The Journal of Laboratory and Clinical Medicine. Mosby, Inc; 2014.163(2):79-98. DOI: $10.1016 /$ j.trsl.2013.08.008

40. Bretaud S, Lee S, Guo S. Sensitivity of zebrafish to environmental toxins implicated in parkinson's disease. Neurotoxicol Teratol; 2004.26:857-64. DOI: 10.1016/j.ntt.2004.06.014

41. Tierney KB. Behavioural assessments of neurotoxic effects and neurodegeneration in zebrafish $i\}$. Biochim Biophys Acta. Elsevier B.V.; 2011.1812(3):381-9. 10.1016/j.bbadis.2010.10.011

42. Panula P, Chen YC, Priyadarshini M, Kudo H, Semenova S, Sundvik M, et al. The comparative neuroanatomy and neurochemistry of zebrafish cns systems of relevance to human neuropsychiatric diseases. Neurobiology of Disease. Elsevier Inc.; 2010.40(1):46-57. DOI: 10.1016/j.nbd.2010.05.010 
43. Khotimah H, Sumitro SB, Widodo MA. Zebrafish parkinson's model: rotenone decrease motility, dopamine and increase $\alpha$-synuclein aggregation and apoptosis of zebrafish. Int $\mathrm{J}$ PharmTech Res; 2015.8(4):614-21

44. Wrangel C Von, Schwabe K, John N, Krauss JK, Alam M. The rotenone-induced rat model of parkinson's disease : behavioral and electrophysiological findings. behav brain res. Elsevier B.V.; 2015.279:52-61. DOI: 10.1016/j.bbr.2014.11.002

45. Xu C, Wang Q, Sun L, Li X, Deng J, Li L, et al. Asiaticoside: attenuation of neurotoxicity induced by mptp in a rat model of parkinsonism via maintaining redox balance and up-regulating the ratio of bcl-2/bax. Pharmacol Biochem Behav. Elsevier Inc; 2012.100(3):413-8

46. Xu C, Qu R, Zhang J, Li L, Ma S. Fitoterapia neuroprotective effects of madecassoside in early stage of parkinson's disease induced by mptp in rats. Fitoterapia. Elsevier B.V.; 2013.90:112-8

47. Chorfa A, Lazizzera C, Bétemps D, Morignat E, Dussurgey S, Andrieu T, et al. A variety of pesticides trigger in vitro $\alpha$-synuclein accumulation, a key event in parkinson's disease. Arch Toxicol; 2014.90(5):1279
48. Berrocal R, Vasudevaraju P, Satappa S. In vitro evidence that an aqueous extract of centella asiatica modulates $\alpha$-synuclein aggregation dynamics. Journal of Alzheimer's Disease; 2014;39:457-65. DOI: 10.3233/JAD-131187

49. Moore DJ, West AB, Dawson VL, Dawson TM. Molecular pathophysiology of parkinson's disease. Annu Rev Neurosci; 2005;28:57-87. DOI: 10.1146/annurev.neuro.28.061604.135718

50. Lotharius J, Brundin P. Pathogenesis of parkinson's disease: dopamine, vesicles and $\alpha$-synuclein. Nature; 2002.3:932-42. DOI: 10.1038/nrn983

51. Yang Y, Jiang S, Yan J, Li Y, Xin Z, Lin Y, et al. Cytokine \& growth factor reviews an overview of the molecular mechanisms and novel roles of nrf2 in neurodegenerative disorders. Cytokine Growth Factor Rev. Elsevier Ltd; 2016.26(1):47-57

52. Uruno A, Yagishita Y, Yamamoto M. The keap1 nrf2 system and diabetes mellitus. Arch Biochem Biophys; 2014. DOI: 10.1016/j.abb.2014.12.012

53. Zhimin Qi, Xinxin Ci, Jingbo Huang, Qinmei Liu, Qinlei Yu, Junfeng Zhou XD. Asiatic acid enhances nrf2 signaling to protect hepg2 cells from oxidative damage through akt and erk activation. Biomedicine \& Pharmacotherapy; 2017.88:252-9. DOI: 10.1016/j.biopha.2017.01.067 